\title{
Decision-Making Model for Business Process Outsourcing of Enterprise Content Management
}

\author{
Zhuojun Yi \\ Sun Yat-Sen University \\ Email: xiaobuzi@hotmail.com \\ Dongming Xu \\ University of Queensland \\ Email: d.xu@business.uq.edu.au
}

\begin{abstract}
Business process outsourcing (BPO) of enterprise content management (ECM) is a growing though immature market. BPO of ECM focuses on pursuing market transactions in the process of managing all types of content being used in organizations. However, inferior sourcing decisions lead to organizationally sensitive content exposure, high transaction cost, poor outsourcer performance, and low flexibility. ECM $\mathrm{BPO}$ in general is rarely discussed in academic literature with any discussion being found on decision-making strategies in ECM BPO. In this paper, we present a decisionmaking model for ECM BPO that will fill the knowledge gap and thus guide industry practitioners with ECM sourcing decision-making strategies. Our proposed decisionmaking model includes two parts. Part 1 involves an ECM functional framework that shows what functionality component or functionality combinations can be outsourced. Part 2 involves a decision-making model that provides guidance for decision making in ECM BPO. We apply the model in two case studies, the results of which indicate that the model can successfully guide the sourcing decision-making process for organizations, and determine the factors when considering sourcing alternatives in ECM.

Keywords: Enterprise Content Management (ECM); Business Process Outsourcing (BPO); Decision-Making Model
\end{abstract}

\section{INTRODUCTION}

Enterprise Content Management (ECM) focuses on managing all types of content being used in organizations. It is a convergence of previous approaches that focus on managing only particular types of content (Grahlmann, et al., 2012). However, the field of ECM is still in its infancy (Smith \& McKeen, 2003) with scientific literature on ECM being limited (Grahlmann, et al., 2012), and ECM business process outsourcing (BPO) still a virgin field. The limited literature gives little insight into how enterprises make strategy, make decisions, and manage ECM business process outsourcing.

BPO is an important strategy for organization management that aims to avoid unnecessary organization expansion, reduce cost of human resources, maximize profits, focus on core competitiveness, and acquire resources/capabilities not available within the organization. Inadequate attention to business processes being outsourced is a major factor contributing to BPO (Aron \& Singh, 2005). Companies spend insufficient time evaluating processes for outsourcing so that what assessment is done is performed too narrowly (McIvor, et al., 2010). 
BPO of ECM has also been developing. PRISM (the global trade association for information management companies) had 586 members at May 2013, 455 of whom were located in North and South America. Although many of the outsourcing companies are of small to middle size, large international examples exist. Using information and communication technologies, more and more functionalities in content management can be supplied from the market. The ECM market, though immature, continues to grow, involving a number of content management vendors (Content Technology Vendor Map, 2013). As the market grows, BPO of ECM becomes a considerable option for organizations.

Nevertheless, ECM outsourcing is different from other outsourcing processes. Besides cost saving and focusing on core business, managers need to look more broadly at ECM. The objectives of ECM in an enterprise have been identified by Päivärinta \& Munkvold (2005) to include: improved internal and external collaboration through digital content in and among enterprises with commonly enacted practices; value-added or new customer services and products; reliability and quality of information content resulting in fewer errors; the modern and professional image of the enterprise; efficiency, effectiveness and flexibility of knowledge work and business processes; meaningful knowledge work involving easier and less tedious human routines; organizational memory recording an enterprise's practice, history and transactions; satisfying external regulations and standards; and platforms and capabilities to develop and maintain targeted applications quickly. The resulting impact of ECM BPO must accommodate, but not be limited to the above objectives. Moreover, risks deriving from outsourcing are one of the critical considerations in BPO of ECM, owing to the information characteristics of enterprise content, such as confidentiality, sensitivity, security and management control requirements, and the transaction cost in the IS field.

On the other hand, ECM is related to information resource management, electronic document management, knowledge management, IT technology and infrastructure. Specialized capabilities attainment is one of the important strategies. Many enterprises seeking BPO of ECM expect better ECM performances through strategic introduction of professional ECM solutions from intermediate market. Therefore, the decision about assessing ECM BPO needs guidance.

However, the literature on ECM BPO is still a blank, according to our findings. This means that how a company decides to conduct ECM BPO or not is critical. As a result, the existing knowledge in BPO is insufficient to guide ECM BPO. This paper develops a decision-making model for ECM $\mathrm{BPO}$, which includes the determinants of the decision-making process for organizations facing the dilemma. We continue through improving the functional ECM framework by Grahlmann, et al. (2012) to explain what can be outsourced in ECM within an organization. Based on the extended functional framework, an organization can employ our decision-making model to determine whether or not to outsource a specific functionality or combination of functionalities.

The remainder of this paper is organized as follows. In the next section, background knowledge is provided, including ECM, ECM functional framework, decision making in strategic business process outsourcing, and transaction-cost theory. The extended ECM functional framework is presented in the subsequent section. We then provide the ECM BPO decision-making model, followed by two case studies which demonstrate the first evaluations of the model. The Conclusion highlights the contributions and limitations, and provides recommendations for future research. 


\section{BACKGROUND}

\section{Overview of Enterprise Content Management}

Grahlmann, et al. (2012) discovered that there is no consensus on the definition of ECM. The definitions found were from different perspectives on content (information, user, system), technology, enterprise, and process. A consistent and comprehensive definition of ECM is that it comprises the strategies, processes, methods, systems, and technologies that are necessary for capturing, creating, managing, using, publishing, storing, preserving, and disposing of content within and between organizations (Grahlmann, et al., 2012). Furthermore, O'Callaghan \& Smits (2005) states in an ECM strategy framework, ECM needs specification, value assessment, cost assessment, content objects portfolio decisions; existing infrastructure (CM staffing included). An ECM strategy framework view is partially consistent with strategic outsourcing decisions, such as value assessment, existing resource, and cost assessment. However, the ECM strategy framework does not take the market into consideration when making strategy.

\section{Enterprise Content Management Functional Framework}

\begin{tabular}{|c|c|c|c|c|c|c|c|c|c|}
\hline $\begin{array}{c}\text { client } \\
\text { application } \\
\text { integration }\end{array}$ & \multicolumn{2}{|c|}{$\begin{array}{l}\text { desktop } \\
\text { application }\end{array}$} & EAl interface & \multicolumn{2}{|r|}{ intranet } & \multicolumn{2}{|l|}{ extranet } & $\begin{array}{l}\text { organization's } \\
\text { website }\end{array}$ & Access \\
\hline \multicolumn{4}{|c|}{ Workflow Management } & \multicolumn{3}{|c|}{ Collaboration } & \multicolumn{2}{|c|}{ Analysis } & Process \\
\hline ad-hoc support & $\begin{array}{l}\text { case handling } \\
\text { support }\end{array}$ & $\begin{array}{l}\text { production } \\
\text { support }\end{array}$ & \begin{tabular}{c|c} 
digital & 1 \\
signatures & 1 \\
1
\end{tabular} & $\begin{array}{l}\text { collaborative } \\
\text { editing }\end{array}$ & $\begin{array}{c}\text { project } \\
\text { management }\end{array}$ & \begin{tabular}{c|c} 
team & 1 \\
communication & 1 \\
1 &
\end{tabular} & $\begin{array}{l}\text { business } \\
\text { activity } \\
\text { monitoring }\end{array}$ & $\begin{array}{l}\text { business } \\
\text { intelligence }\end{array}$ & \\
\hline
\end{tabular}
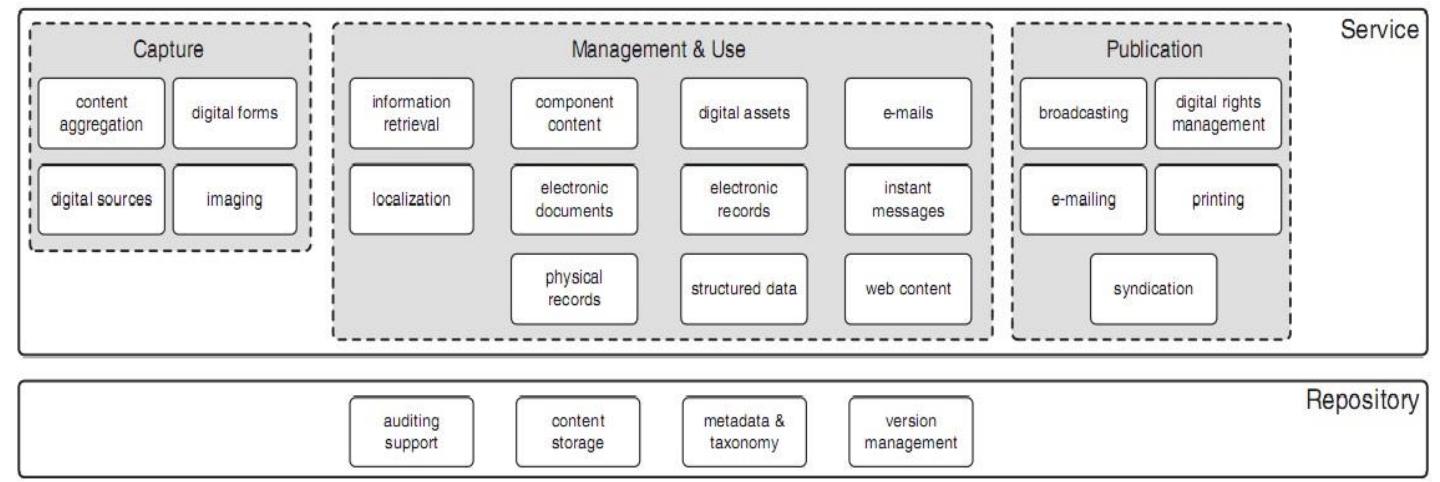

Figure 1: Functional framework (Grahlmann, et al. 2012)

Grahlmann, et al. (2012) summarized the functionalities that an ECM can provide. The access layer refers to functionalities for users and information systems to interface with the ECMS in order to retrieve content and/or to use/invoke other functionalities. Functionalities related to control and coordination refer to the process layer, while those related to capturing, manipulating, using and publishing content refer to the services layer. The fourth repository layer includes the functionalities related to the storage and preservation of content. According to the guidelines of Grahlmann, et al. (2012), the framework is comprehensible, usable, complete, generic enough to be suitable for making comparisons, distinguished enough for capturing differences, and future-proof. This original functional framework indicates directions of analysis units' segmentation. According to this 
framework, enterprises can use an ECM function or a functionalities combination as the analysis units for making evaluations.

\section{Overview of decision making in strategic business process outsourcing}

Since analysis units have been discussed in the last section, the next question is which ECM unit can be outsourced. Therefore, in this section, we explore the theoretical background for ECM outsourcing and sourcing decision. In strategic BPO, outsourcing results and the core competency issue as the driving force are discussed in the literature. The resource-based view is also widely discussed in the BPO literature. Achieving sustained competitive advantage is discussed as another driving force and important issue to outsourcing other than focusing on core competency and cost saving. In the final section, the literature discussed decision making in sourcing.

Holcomb and Hitt (2007) define strategic outsourcing as the organizing arrangement that emerges when firms rely on intermediate markets to provide specialized capabilities that supplement existing capabilities deployed along a firm's value chain. Holcomb and Hitt (2007) also provide three possible economic motives behind strategic outsourcing: reducing bureaucratic complexity, improving production economies when firms fail to achieve sufficient production scale to overcome cost disadvantages, and financial advantage. Furthermore, Quinn and Hilmer (1994) suggest that one of the concentrates for strategic outsourcing is a firm's set of core competencies where it can achieve definable pre-eminence; the other of the concentrates is for outsourcing other activities which are neither critical nor something in which the company has special capability. Gilley and Rasheed (2000) identify substitution-based and abstention-based strategic outsourcing. As a result, strategic outsourcing creates cost economies, also creates economic value, especially when production involves the use of potentially more valuable specialized capabilities (Fine and Whitney, 1999; Mowery, et al., 1996).

The theory of firm resources and sustained competitive advantage (Barney, 1991) has been the foundation theory for strategic business-process outsourcing. Because of firm-resource homogeneity and immobility, not all firm resources hold the potential of sustained competitive advantage. Therefore, a resource-based view in strategic outsourcing concerns the role of specialized capabilities obtained through intermediate markets. Holcomb and Hitt (2007) address those four different conditions affecting the value of capabilities sourcing from intermediate market: complementarity of capabilities, strategic relatedness consisting of goal congruence and commonality of knowledgesharing routines, relational capability-building mechanisms, and cooperative experience.

Sourcing decisions have their origins in make/buy alternatives (Tayles \& Drury, 2001). Tayles \& Drury (2010) develop decision-making logic for manufacturing companies, ensuring wider issues are considered in a logical manner based on RBV theory. Their sourcing-decision model not only applies to transparent and operational activities, but also to non-manufacturing activities such as support services. The starting point of Tayles \& Drury's (2010) model is whether the process or component is prima facie strategic, according to a core competencies focus. The next logical question involves the cost associated with in-house build or out-sourcing, which is supported by cost economies theory. The model considered strategic review in the sourcing decision-making process. If the process or component is not deemed strategic, the decision would go to whether the company possessed the capability. If it does not, and a supplier exists that can satisfy the company's needs regarding quantity, quality, delivery and price, then the company should buy, which means pursuing outsourcing. If the capability exists in-house, resources are available, and their use is shown to be economical, then the company should retain them in-house. Transaction cost is an important aspect when conducting strategic outsourcing also. 


\section{Overview of transaction cost theory in IT outsourcing}

Transaction cost is a crucial consideration in IS outsourcing (Alvarez-Suescun, 2010). Aubert \& Weber (2001) said decision-makers must weigh up the production and transaction costs associated with executing a transaction within their firms (insourcing) versus the production and transaction costs associated with executing the transaction in the market (outsourcing). It's argued that environmental factors- asset specificity, uncertainty, and small numbers trading affect the type of governance decision for a transaction (Williamson, 1985).

Williamson (1985) is unequivocal about the primacy of asset specificity. Aubert, et al (2004) states that assets can be machinery required to manufacture a product, knowledge needed to perform a service, or even appropriate location convenient for dealing with the other party. Aubert \& Weber (2001) argue that the essence of asset specificity is that lock-in effects occur, which potentially lead to hold-up problems. When asset specificity is high, regardless of investments in physical or human capital, the investor needs an insurance contract or mechanism to protect itself.

Increased uncertainty in a transaction will lead to increased use of internal governance. Two types of uncertainties has been addressed (Aubert, et al., 2004). One type is demand uncertainty, referring to parties who do not know ex ante the volume that will be required or ignore the form the service will take. Another type is related to measurement. Evaluating the service or product, in terms of quality, quantity, and timeliness is of great importance when parties step forward to the contract negotiating stage. The uncertainty is also related to contingency. There may be too many contingencies for an exhaustive list to be drawn, and they may be too complex to estimate the probabilities. These kinds of uncertainty also increase transaction cost.

Lacity and Willcocks (1995) specify a transaction as either occasional or recurrent, to measure frequency. Aubert, et al. (1996) argue that low frequency transactions are likely to be organized through market interactions or with the help of any general governance mechanism available in the community. Rather than create new governance or expanding an existing one for low frequency transactions, firms are more likely to bear the risk. And internalization of transactions by the firms is only efficient for recurrent transactions (Aubert, et al., 1996).

The transaction cost framework can explain sourcing behavior, such as the choice of sourcing and the contract between a firm and its outsourcer. According to the framework of Aubert, et al. (1996), for the transactions with high-asset specificity, internal governance is expected to apply to those, of which high uncertainty combines with high frequency. When transactions have high asset specificity, low frequency, but high uncertainty, relational governance can emerge. In this framework, a complete contract for outsourcing applies to transactions of high-asset specificity and low uncertainty.

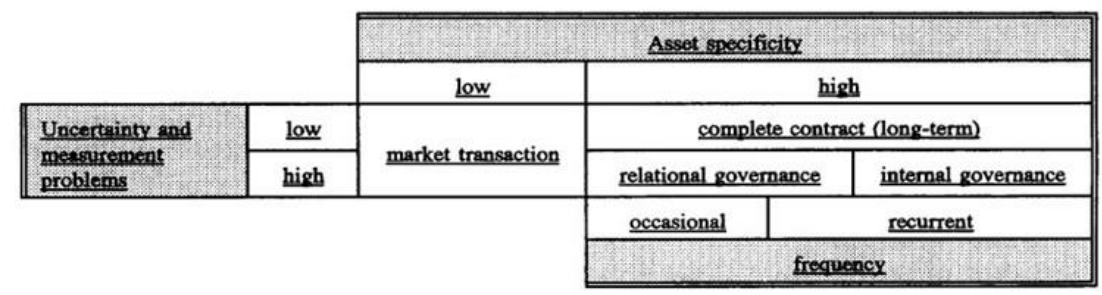

Figure 2: Transaction cost framework (Aubert, et al, 1996) 


\section{DEVELOPMENT OF BPO DECISION-MAKING MODEL OF ECM}

\section{ECM Modelling}

An ECM model may divide ECM into transactions or amounts of specific functionalities, which are able to show which part of the ECM transactions can be analyzed, evaluated, and even used to conduct market transactions or outsourcing. In the first sections, we need to re-examine the functionalities of ECM, and thus generate an ECM functional framework. What follows determines the factors in decision making in ECM BPO, leading to the next section, where we develop our decision-making model.

\section{Paper-based content}

ECM in the information system field mainly focuses on managing digital-based content or strategies, processes, technologies, and methods for managing digital-based content, which does not accord with 'all types of content'. In the functional framework by Grahlmann, et al. (2012), all functionalities in the access layer are digital related or information communication technology based, involving clientapplication integration, desktop application, EAI interface, intranet, extranet, and the organization's website. Functionalities like physical records and localization have been mentioned in the service layer, but they can only be accessed digitally. Furthermore, other functions based on paper-based content are not included in the repository layer, such as physical records which can be evidenced in legal affairs. Therefore, a paper-based content view should also be adapted in the functional framework.

The scarce ECM literature mentioning paper-based content led us to look at the records management and archive management literature in general as a supplementary knowledge basis for our functional framework. According to American archival theory, current records are looked upon as future archives to provide advice on how they can best be handled. Management of semi-current records and current records led to important thought and action in the establishment of records management programs (Pinkett, 1981). The life span of a record from creation to final disposition is called the record cycle. It begins at creation, followed by classification, storage, and retrieval. After a determined period of time, records are transferred to other places — perhaps within the organization to a less expensive storage site in terms of overhead costs. Appraisal is the function of determining whether to retain forever or a stated number of years based on the value of records. At the end of the stated number of years, the record is destroyed or put into the archives, a permanent storage place (Zhaoyu, 2008).

In the book "Modern Archives", Theodore R. Schellenberg (1903-1970), puts forward the ideas of the primary and secondary value of records. Primary value is based on a record's administrative justification, while secondary value is rooted in the historical and evidential value. Schellenberg divides the secondary value into evidential and information value. Records with evidential value document the organization and functioning of the creating agency (Stapleton, 1983). Reference service is another important functional area. It is based on the view that public records or records in a public repository should be available for use to the maximum extent consistent with the public interest. A reference service may increase the availability and use of archives. Meanwhile, maximum accessibility must be balanced with a concern for individual rights, legal safeguards for personal privacy, public security, and intellectual property.

In archives management, records survey and statistics of collection and use of records are routines and the basis for the whole management, which provide measurements for paper-based records transactions, such as the volume, and records services quantity and quality. When the organization 
considers intermediate storage, records center, destruction services, and related services from market sourcing, statistics from records survey provides a means to decrease the uncertainty of organizational demand and requirement.

\section{ECM functional framework}

According to the "all types of content" definition of ECM, a paper-based view should be added to ECM functions. We called it the extended functional model based on the functional framework by Grahlmann, et al. (2012). In developing countries, paper-based content, also called records, documents or archives, is the dominant type of content within organizations. Resources devoted to information systems may be considered less competitive than those devoted to capital assets, equipment, facilities, etc. Enterprises in developing countries are less likely to manage and retain all content in information systems or data centers. Most firms implement some types of content management software or systems; but the measures adopted tend not to be reliable, safe or capable of storing and maintaining easy access to digital content, nor to have enough technology and resource support. 'Paper-based' is still the choice for most firms in developing countries, since paper-based records can support the basic content management requirements within organizations.

We extract five specific management functions from both records and archive management to supplement paper-based content functionality in the ECM model. The five added functions do not overlap the existing functions in the original framework by Grahlmann, et al. (2012). In the access layer, the function of the records management department is listed as the entrance for paper-based content. The records management department may use aids such as a catalogue, a general inventory, or an index list. The department may also provide reference services to direct access the content. In the repository layer most like archive management functionalities, we add two more uses for the content function/value: reference and evidence values. The archive management sub-category is developed in the same layer, including appraisal and records survey as the last two adding functions. The ECM functional model is demonstrated in Figure 3.

Some of the functions are identical, overlapped, or similar to both digital-based and paper-based content management. Accordingly, we do not add records or archive management terms of these functions in the model. For example, content aggregation delivers similar function of records collecting or acquisition. Imaging is the technique of transforming paper-based content to raster objects. Information retrieval can apply to digital-based and paper-based content. Localization refers both to where to keep the digital-based or paper-based content, and where to transfer them. Physical records refer to the management and use of paper-based content or content in other physical carriers. Printing is the method of transforming digital-based content to paper-based. Content storage is needed in the repository layer for both digital- and paper-based content. Archival description contains the metadata function such as the data set name and data fields as well as similar information. The taxonomy shown in Figure 3 is a system of classification for digital- and paper-based content. Version management not only refers to versions of content management software and different digital formats transforming, but also refers to the historical versions of specific records as well as the original copy and duplicate/backup copy for digital- and paper-based content. Overall, both digital- and paper-based content can support auditing function in ECM.

In our case study section, we apply the ECM functional model to exemplify the content management components in enterprise. Based on the framework shown in Figure 3, organizations may go forward to the sourcing decision-making process. 


\section{Factors in Decision making for BPO of ECM}

According to the ECM functional framework, an enterprise can use an ECM function or a functionalities combination as the analysis units, then make outsourcing evaluations. There are three groups of factors that drive ECM BPO decision. One group of factors is estimated sourcing decision results while others involve factors to consider in the ECM BPO model shown in Figure 4 and Figure 5. The sourcing decision in ECM is identified in the first sub-section; the important issue of core competencies relatedness is discussed in the second sub-section, along with several other informationfeatured considerations; and finally, in the third sub-section we discuss other considerations in the model.

\section{Sourcing Decisions}

There are four outcomes for the model, which are the same for the two decision-making figures we discussed. "Make" refers to adapting internal management strategy without additional resource. "Invest/acquire resource" also adapts internal management, but through internal sourcing to acquire necessary resources. "Partial outsourcing" means a relational management style, the enterprise, and the outsourcer developing a cooperative relationship. "Outsourcing" stands for substitution-based outsourcing, pursuing external management, discontinuing internal management, and replacing existing activities or processes with capabilities provided by an intermediate market.

Contract type is related to asset specificity. When the outsourcer invests in an asset to support a transaction, the asset may have little or no value apart from that transaction. If the asset specificity is low or acceptable, ordinary contracts may be used for short-term situations. If an asset is highly specific to the transaction, the investor may use an insurance contract to minimize cost. One type of insurance contract is long-term, where an adequate period of time is locked in and the cost of the investment is more likely to be recouped.

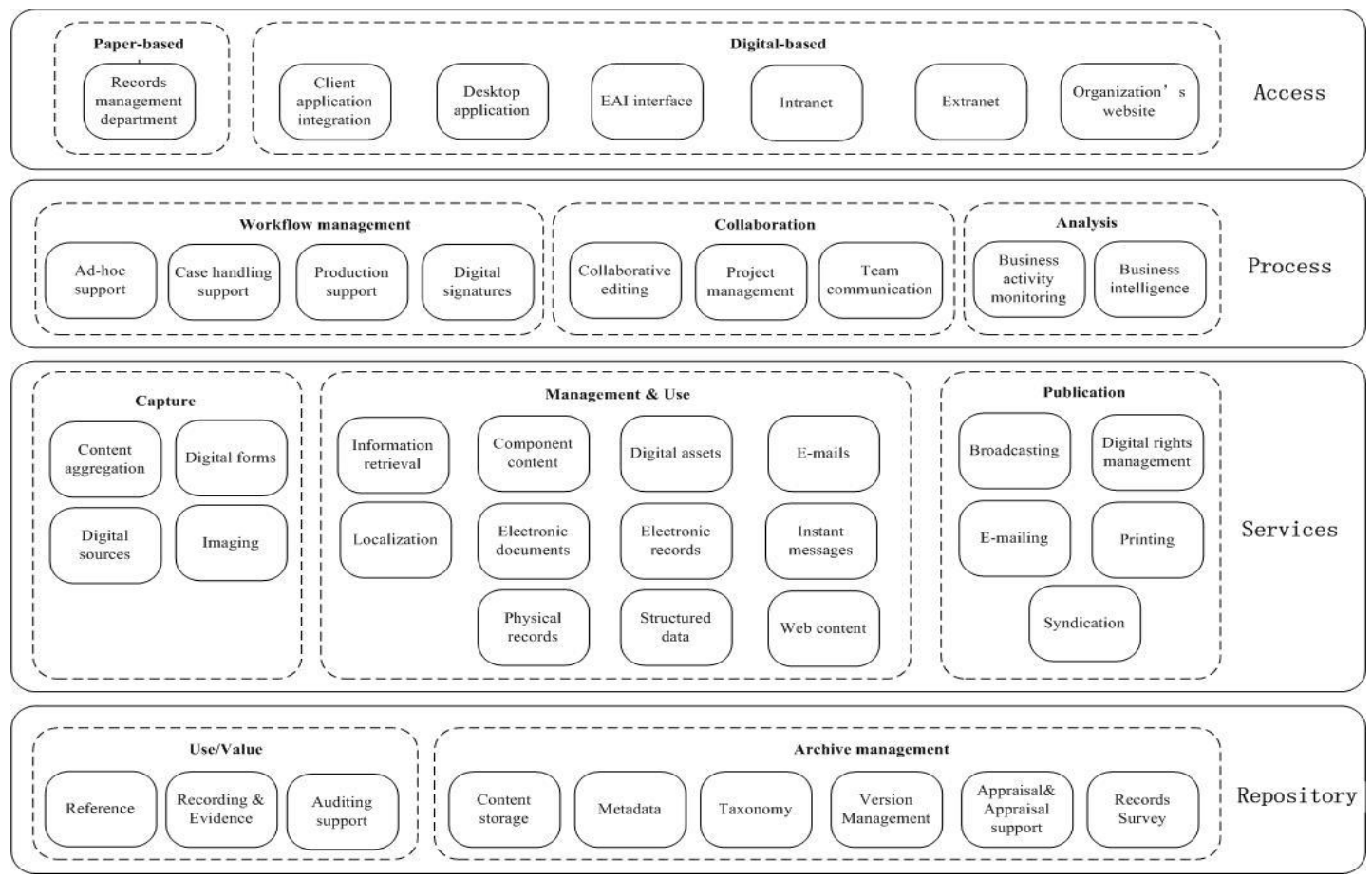


Figure 3: ECM Functional Framework

\section{Core Competency Relatedness}

The logical starting point for our model is the question as to whether ECM functionality relates to core competencies or not. ECM functionality relates to core process/key source/strategic component usually existing within the enterprise in particular forms, like activity monitoring, business intelligence, work-flow management and project management, owing to the supportive and monitoring functions of ECM. The process or functionality in ECM is highly revealing of the content or information. Firstly, information confidentiality requirements would be extremely high for ECM outsourcing related to core competencies. Sensitive or confident content should be shared within a specific range of people and departments in the organization. An ECM function revealing confidential or sensitive content is more likely to be kept under internal management. However, there are other means to protect confidentiality such as limiting exposure of confidential content by segregating confidential information to keep it internal. If this is a practical option, then the next consideration in the decision-making process can be addressed. If not, it is better to return to in-house management. Another way to protect secrecy is by outsourcing in partnership (partial outsourcing), by which the enterprise outsources the equipment, technology etc. to obtain the necessary resources and capability, but does not outsource the actual management process or functionality. Secondly, there would be no tolerance for information insecurity for ECM outsourcing related to core competencies, which should apply higher information security standards and provide the resources required to maintain security standards. If security standards can not be met, the decison should return to internal management or relational management. However, for ECM functionality not related to core/process/key resource/strategic component, there is an extended tolerance for information insecurity. Thirdly, management control must be maintained within the organization for ECM outsourcing related to core competencies. Yang, et al. (2006) noted that the most prominent risks in outsourcing are to information security and loss of management control because an enterprise needs to maintain management control for ECM functionality related to core competencies. In the condition of lost management control, process and spec of the specific ECM functionality should be changed. Fourthly, there is little scope for flexibility for ECM outsourcing related to core competencies. Flexibility in management is valued above maintaining control in non-core competencies related circumstance. Yang, et al. (2006) argue that outsourcing non-core activities also increase flexibility through the better use of internal resources, enables quick responsiveness to customer needs, and decrease financial risks by reducing capital investments. When the flexibility evaluation is low, the process or services being evaluated should be modified.

\section{Other Considerations}

Firstly, the cost of the ECM functional process conducted in-house and outsourced must always be compared. If the cost to maintain the process in-house is cheaper than outsourcing, the next question is whether the capability is available within the organization. Internal management by Make is the decision when resource and capability exist in the enterprise. When the answer is no, if the cost of Make (incurring the necessary investments to internalize the process) is cheaper than the Buy resource or capability from the intermediate market, the next question is whether the resource can be acquired. If it can be bought, the decision goes to internal management through investing or acquiring resources. If Buy is cheaper than Make, or the resource cannot be acquired by the enterprise itself, partial outsourcing is conducted to obtain requisite resource or capability.

Secondly, when transaction cost evaluation is necessary for the enterprise to evaluate asset specificity, uncertainty and frequency separately, we apply the transaction cost framework by Aubert, et al. (1996) to determine the evaluation. Whenever the asset specificity is low, market transactions should 
be considered with priority. If asset specificity is evaluated as high with low uncertainty, outsource under a long-term contract is likely to emerge. When high uncertainty combines with high frequency, it is better to maintain internal government or management. If high uncertainty combines with low frequency, relational management should be conducted. Therefore, if market transactions and outsourcing contracting will occur in an organization, then transaction cost evaluation is true and a decision will next take supplier availability into consideration; otherwise, if the relational government and internal governance will be employed and then the decision will take resource/capability availability into consideration.

Thirdly, supplier availability in the subject conditions cannot be ignored. In addition, the average level of suppliers' services or production quality is an important concern. If the market does support such ECM functional transactions with acceptable quality in the mass, the decision can step further to the confidentiality question.

\section{Model Development}

The logic for ECM sourcing decisions is developed to link all considerations and decisions' results. In the light of Tayles \& Drury's (2001) decision-making logic for manufacturing companies, our sourcing decision-making model develops the logic for ECM sourcing to ensure that all issues are considered in a logical manner. We develop two figures to demonstrate the sourcing decision-making processes for ECM functionality related to core competencies and those not related to core competencies respectively, since the core competency issue is the starting point of our model. The model is developed into sequential consideration logic. Simply by going through the former consideration and getting the appropriate evaluation result, the decision can lead to the next consideration. If an evaluation gets an inappropriate result, the decision would take the other direction shown in Figure 4 and Figure 5, or need to change the process or spec and start again. For example, if the ECM functionality is not related to core competencies and also not existing within the organization, it is an innovation to pursue these ECM functions from market sourcing. Supplier availability and transaction cost evaluation are the next two logical questions. Then the cost acceptance is taken into account whether the new added functionality in ECM can be financially justified. If the answer is yes, information insecurity tolerance should then be evaluated. With high insecurity tolerance and high flexibility, the new ECM functionality can be outsourced. If any one of (i) a supplier is unavailable, (ii) the transaction cost evaluation has no result, (iii) the cost is unacceptable, (iv) there is low information tolerance, or (v) there is low flexibility is the case, the enterprise should change the process or spec and go through the decision-making steps again. 


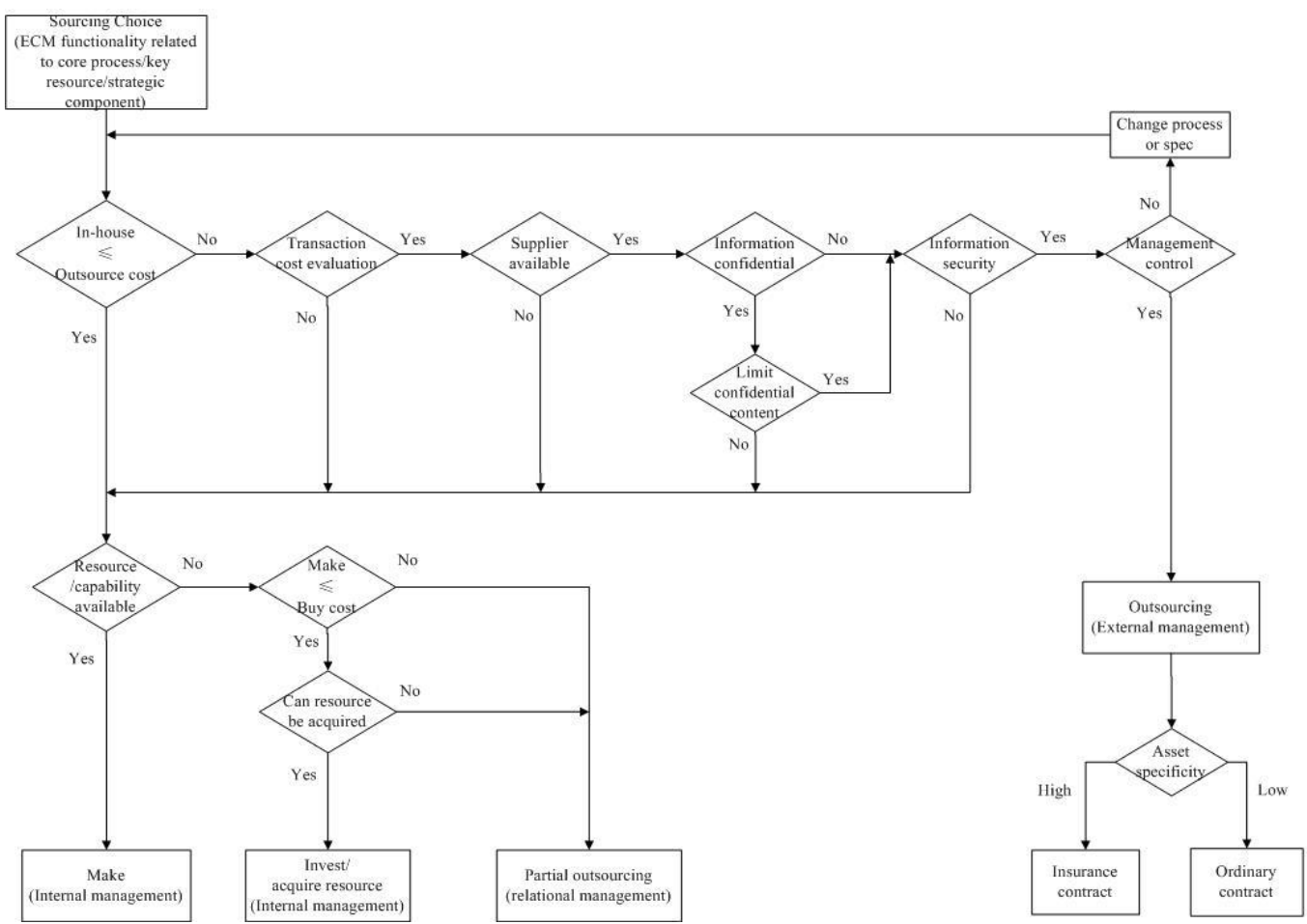

Figure 4: Decision making model (ECM functionality related to Core competencies)

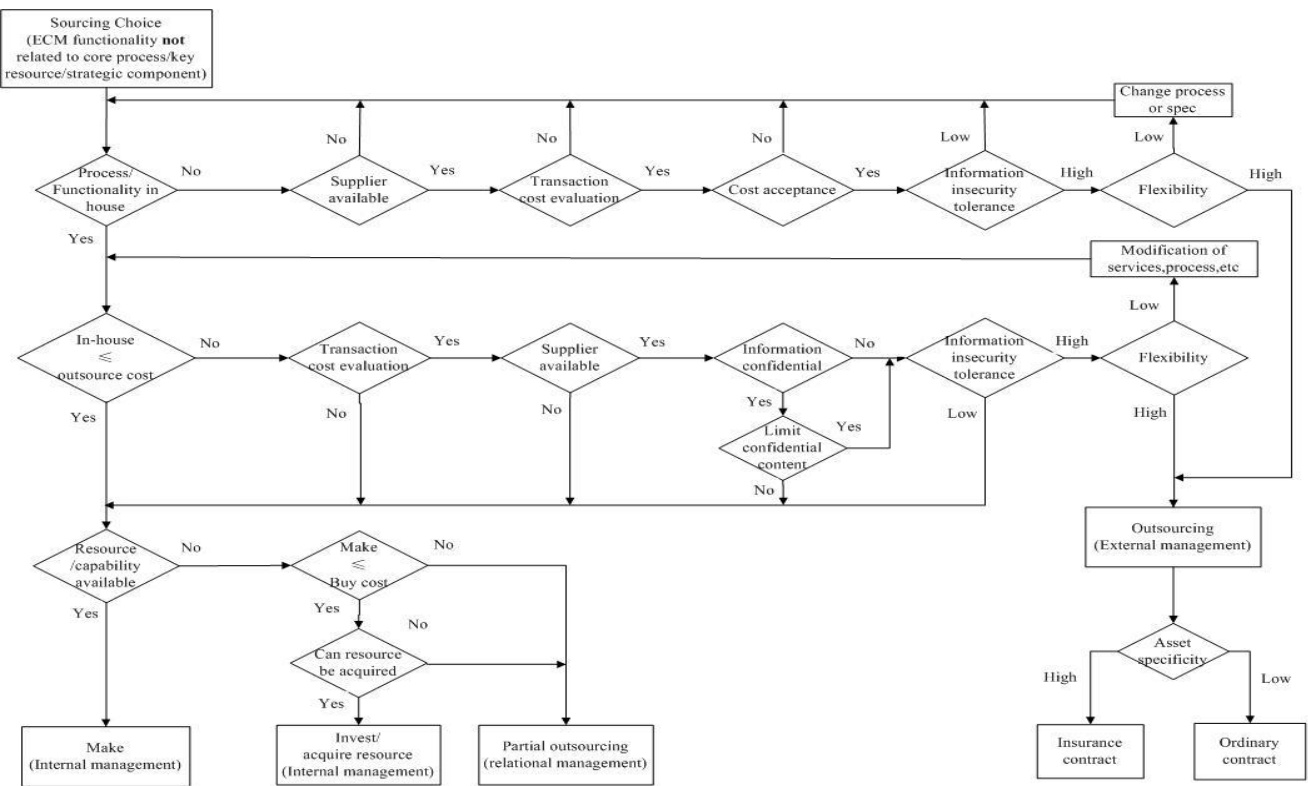

Figure 5: Decision making model (ECM functionality not related to Core competencies) 


\section{CASE STUDY}

\section{Methodology}

Roethlisberger \& Lombard (1977) suggest that case research is particularly appropriate for certain types of problems: those in which research and theory are at their early, formative stages. Bonoma (1983) adds sticky, practice based problems where the experiences of the actors are important and the context of action is critical. In this paper, case research enables research in a natural setting. Rather than participation, the observation and investigation in the case study can test our model inside a natural setting. Moreover, the implementation of the decision guided by our model is a complex process involving multiple actors and is influenced by unexpected events. Benbasat, et al.(1987) argue that a case study methodology is well-suited to identifying key events and actors and to linking them in a causal chain. As a result, we adopt a case study with a two-case design. The two cases cover two types of enterprise contents: digital-based and paper-based content, and two corporations, a realty development company and an electric power plant. They will yield more general research results, and indicate how the model may be extended.

As to the selection of the organizations, the case study can only be conducted if the organization has experienced the ECM outsourcing process or is confronted with the outsourcing decision. Generally, those organizations paying close attention to internal information management intend to outsource or partially outsource ECM, because they recognize the asset value of the content. So the organization selection would focus on those emphasized on content or information management.

\section{Evaluation Criteria}

Kung \& Cheng (2004) contributed to the evaluation criteria that affect the performance of outsourcing activities. Five categories of performance evaluation criteria have been extracted, which are efficiency, quality, innovation, customer responsiveness, and integration capability. These criteria are based on firm level. But in the ECM outsourcing field, we looked further than production, research and development, and innovation might not be a proper factor to evaluate outsourcing performance, choosing rather to consider factors at both process and firm level. As a result, we turn to literature focusing on information system outsourcing. Wang, et al. (2008) stated that the expected benefits for IT outsourcing include cost reduction, improved cost control, improved technology or technical service, focusing business on core competencies, access to new technologies and technical talents, and improved flexibility. The outcome measures that adapt both the process- and firm-level view comprise expectations realization, the satisfaction with technological, strategic and economic benefits and market value of the client firms.

We found that integration capability is the factor included by both firm- and process-level evaluation. Besides, we chose seven factors among the above for our evaluation of ECM outsourcing performance, which are efficiency, quality, customer responsiveness, cost saving, and focusing on core competencies. We applied our models in two case studies in which we derived the impacts of the sourcing decision in ECM based on the above criteria.

\section{Real Estate Sales System}

In this case, the realty industry enterprise is located in southern China and has been developing different kinds of real estate for more than 12 years. It is a middle size, single-billion Renminbi Corporation, with 238 employees. The enterprise operates several construction sites in different cities, and sells them when projects are finished. Construction projects managers manage individual sites, but the sales management and control remain at headquarters. The sales volume reached 4.2 hundred millions RMB in 2010, 4.5 hundred millions RMB in 2011, and is scheduled to double in the near 
future. The sales department is directly under the CEO of the enterprise, and is responsible for establishing overall sales policies and strategies including competitive positioning, business collaborations and policies, and strategies for sourcing decisions.

In keeping with its sales management purposes of centralization and distinctiveness, the sales department decided to strip most sales operation processes from the office automatic system, and transfer them to a new sales system. In the meanwhile, the ECM functions related to sales are crucial to sales management and the whole capital chain in the enterprise. It became a question for the heads of the sales and information department as to how to source the ECM functionality in sales. The ECM functionality needed in this case is embedded in the whole sale process/component, and is illustrated in our ECM model in a grey background in Figure 6. Most of them are digital-based content functions. Although some of the functions exist in the sales system, as desktop application, project management, business intelligence, information retrieval, and version management, more is needed, such as the EAI interface with the existing financial system and office automatic system, case handling support, collaborative editing, monitoring, content aggregation, electronic records and taxonomy etc.

The decision-making process that we derived through semi-structure interviews is illustrated in Figure 7 in a grey background. The ECM functionality related to sales management, which is definitely the core process and strategic component to the realty development enterprise. First of all, they stated that the human cost of designing ECM functionality in systems within the organization was impossible. Whether the enterprise developed these ECM functions in the sales systems or relied on the old office automatic systems to link up to the new sales system, the costs were unacceptable if its sales department conducted internal sourcing. So the decision went to market transactions. Secondly, interviewees considered questions about transaction cost evaluation. We found that the design of the ECM functions in the system is occasional, while the use of these functions is recurrent. Furthermore, the outcome of the functions' application design is not uncertain as long as they can control the contract with the outsourcer. They found out that sales-related ECM functions existed in other companies in the same industry. The functions illustrated in Figure 6 were in the low level in asset specificity. Undoubtedly, the content relating to sales was sensitive and confidential, which cannot be avoided in the management, use and storage of them. After the above considerations, the enterprise decided to outsource the design and programming of the ECM functions they needed. As a result, they started to negotiate with the supplier of the new sales system on whether they could achieve these ECM functions in the new system. According to the existing ECM functions in the original sale system, the supplier added the absented functions in Figure 6. The contract between them was modified, limiting the technological support and consultancy by the supplier after the system was put into effect. The realty company and the sales system vendor developed a cooperative relationship in the implementing of and training in the new sales system and ECM functionality related to sales. 

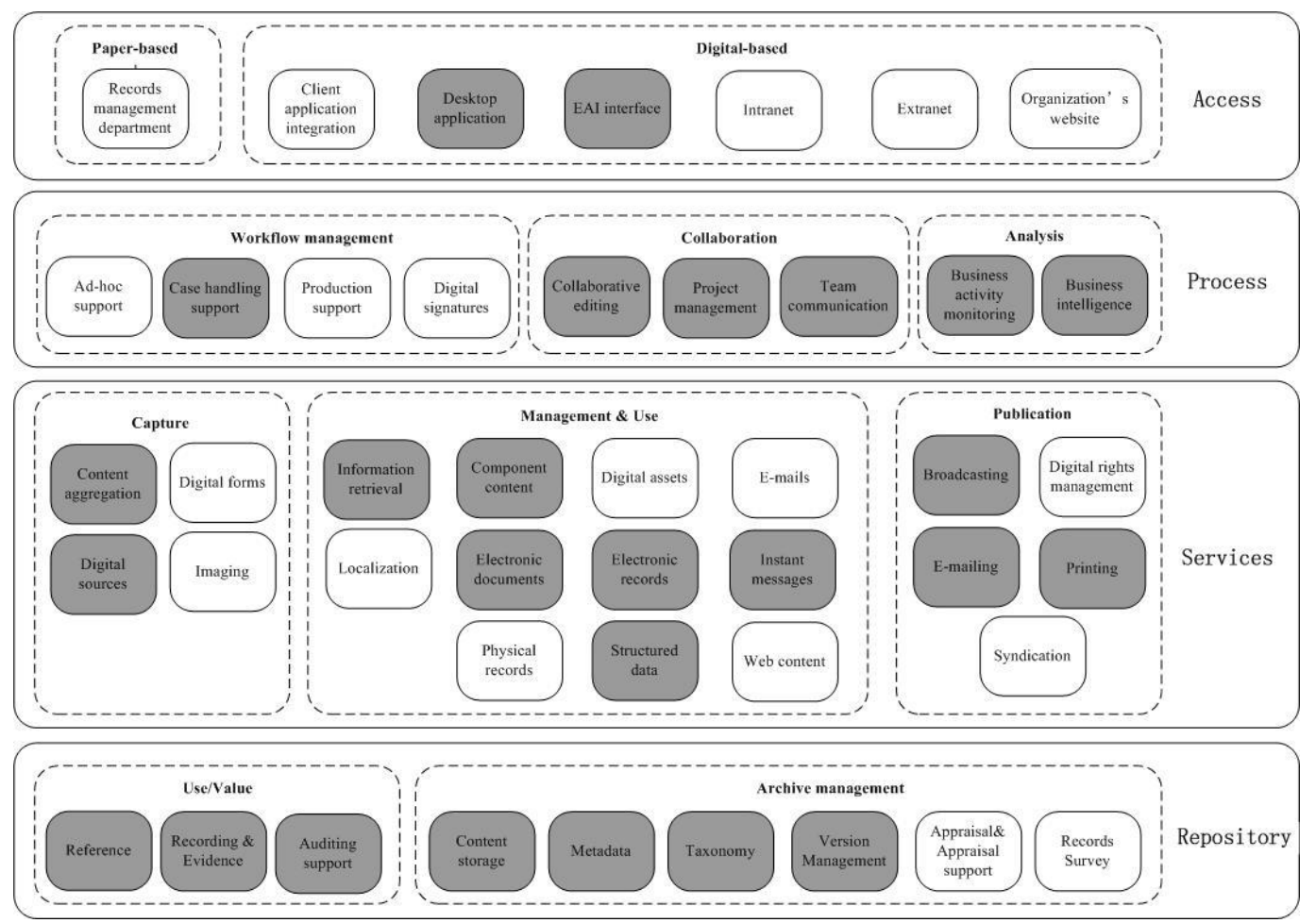

Figure 6: The needed ECM functionality in real estate sales system

The practical application of the decision-making model during the case study indicated that the model can generally guide decision making. The realty development enterprise followed the logical process in the model and went to the right sourcing decision. This led to benefits derived from enhanced IT performance leading to enhanced efficiency of sales management; faster structured data aggregation, case handling, and collaborative editing contributing to the efficiency and the customer-response factor; and new price policy and discount approval decisions available faster to sales or real estate management advisors so that deals can be made faster. In addition, sales performance can be analyzed daily or weekly rather than monthly, which is the former expectation to the modification flexibility. After the taxonomy adjustment, the storage of electronic records and different version sales policies can serve the needs for authorized internal consultancy, the quality of which can support auditing and reference. As the major purposes of outsourcing, cost saving and focusing on core competency, the relational management decision contributes most. The modified contract developed the links among each of the sales, financial, and office automatic systems, included test, secondary development and following training, with the $78 \%$ price of the basic sales system and being half the price of the office automatic system. Most important of all these evaluation factors, the cooperative-relationship decision let the enterprise focus on carrying forward constructions and promoting its sales. 


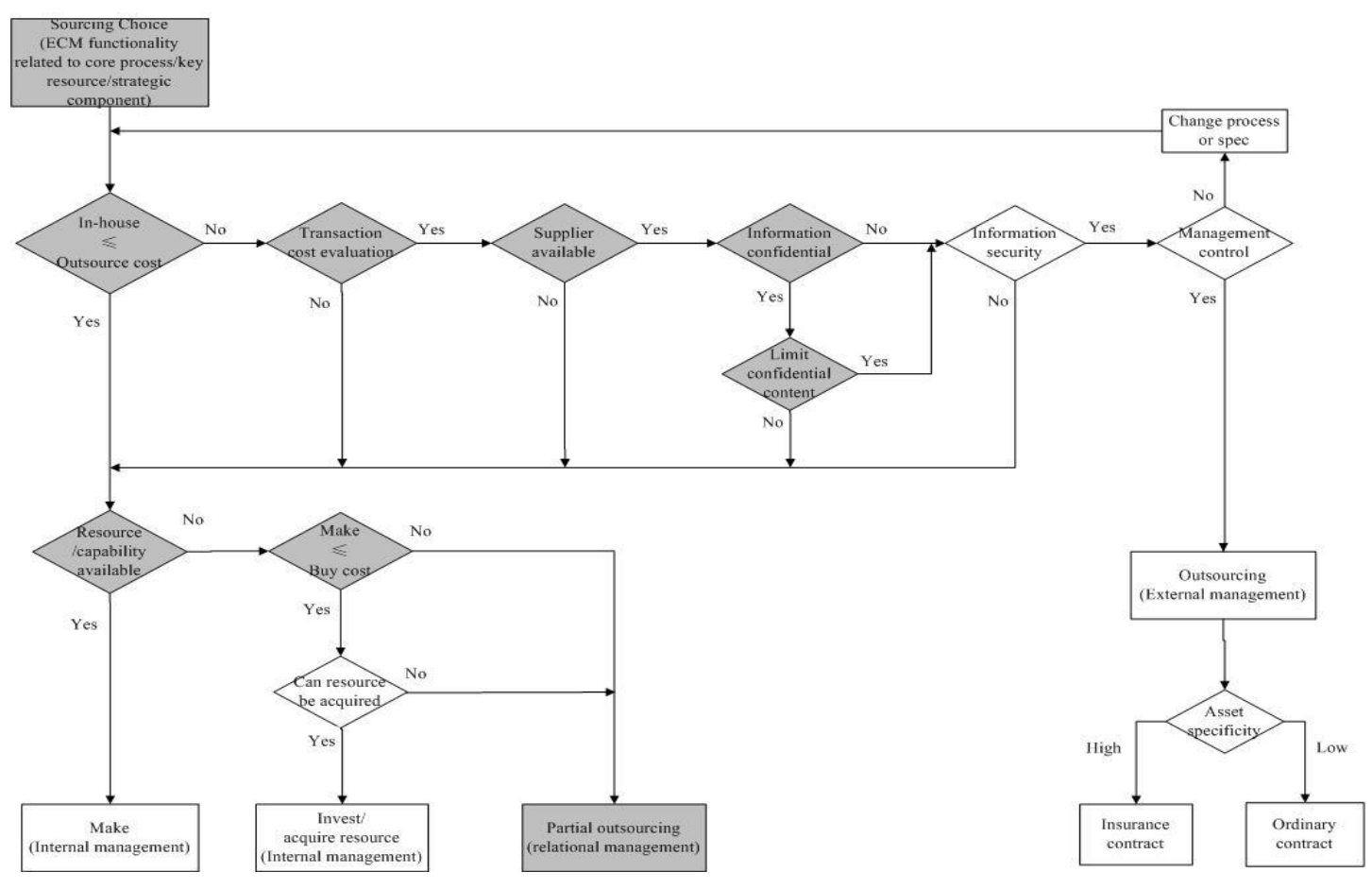

Figure 7: The ECM sourcing decision for the real estate sales system

\section{Power Plant Extension Construction Archives Project}

The power plant is a state owned corporation located in the suburbs of a second-line city in southern China where it generates electricity and feeds it into the power grid managed by China Southern Power Grid. Because of the skyrocketing energy needs in and around the city, the power plant was going to implement the strategy of extension, and increase production progressively. The addition of new generators was the strategic component in the extension, while a new office building and other facilities were also needed. The power plant established a committee to take charge of the whole extension project. To fulfill the office building and its related facility requirements, after the committee finished public bidding for construction units and construction supervision unit, it consulted the City Construction Archives to find that it had full responsibility in the construction archives projects and its final acceptance.

As a result, the committee started to ascertain the function scope in the construction archives project and found that the content related to the new office building and facilities was not related to core process or key resource. The ECM functionality in the construction archives project is illustrated in our ECM model with grey background in Figure 8. These functions are paper-based and digital-based mixed. According to the regulation of the City Construction Archives, the power plant needed to manage the whole archives project, including monitoring the construction recordings in the standard for Guangdong Province construction project completion acceptance technical documentation. The committee needed to ensure that the recording was consistent with the construction by aggregating recordings from construction units and supervision unite, arranging and storing all physical records with classification, and transferring back-up copy to the City Construction Archives in the final stage. Furthermore, the construction archives project is coincident with the construction project. 
The committee divided the project into two components. Component one is the power plant extension construction archives project, component two is the content storage for the construction archives. The decision-making process for component one is illustrated in our decision-making model with grey backgrounds in Figure 9. Although the archives management and records management process existed within the organization, there were gaps between the existed capability and the capability needed in the project. Since the construction archives project is coincident with the construction project, the process and schedule can be influenced by many factors like capital chain, waiting for architectural planning approval, etc. Herein, human resource use is not intensive but lasts a long period. The cost of internal management was not worthy in the judgment of the committee. Afterwards, they started to think about outsource cost. In this particular example, the construction archives project is highly specific to the extension transaction, but the uncertainty of it is relatively low due to regulations by City Construction Archives. Even if the transaction continues for a long period, it is occasional and unlikely to be repeated in at least five to eight years, so the transaction cost evaluation was agreed to by the committee. Furthermore, a local outsourcer with good relationships with some state-owned enterprises and some departments of city government was available. In addition, the content revealed through these construction transactions was not confidential, because the building artificial intelligence system and security system development would come after the construction complement and acceptance. Except for some important licenses and articles of the construction project received from the government, the archives project had high tolerance for information insecurity. The committee negotiated with the outsourcer about the flexibility. As a result, the outsourcer was to send one full-time staff to the construction site during the whole period, while professional data processors could be called on when needed during the construction stage. Furthermore, professional consultants could also be reached by the committee. Owing to the highasset specificity of the archives project, the outsourcer and the committee agreed on an insurance contract, in which the cooperative relationship lasted for the whole basic construction period, and the payment schedule was also laid out and agreed to by both parties.

Besides, the committee recognized the importance of the component tow - content storage, and its high-asset specificity to the localization and storage of the whole power plant extension project. Component two involves the expansion of the storage capability in the archive office to make room for the construction archives and records related to new generators' purchase, test, operation and maintenance. The decision-making process for component two is presented in Figure 10.

The committee of the power plant admitted that the decision-making model could guide the sourcing decision-making process for organizations. The decisions let the committee focus on core components and key resources including the purchase, logistic, assemblage and test of the new generators. The cost saving was presented in such a way to reduce long-term human resource cost. The power plant was able to get in professional advisors when they needed. The on-site staff from the outsourcer liaised between the power plant and the outsourcer, monitored on behalf of the owner, and even arranged the records for the enterprise. By getting in such professionals, the quality of the construction archive project could be ensured to a certain extent and thus assist the power plant to gain acceptance from the City Construction Archives. Right up until this paper was written, the construction archives project was moving to the final stage, with both the committee and the outsourcer looking confidently to final acceptance within half a year. Also it is an important way to integrate professional construction archives capability and professional storage capability. Through the outsourcing contract, the power plant develops a widen horizon and better understands the content storage function and other ECM functionality. The internal reference and evidence functions are clear for the future goals of the power plant ECM functionality. 

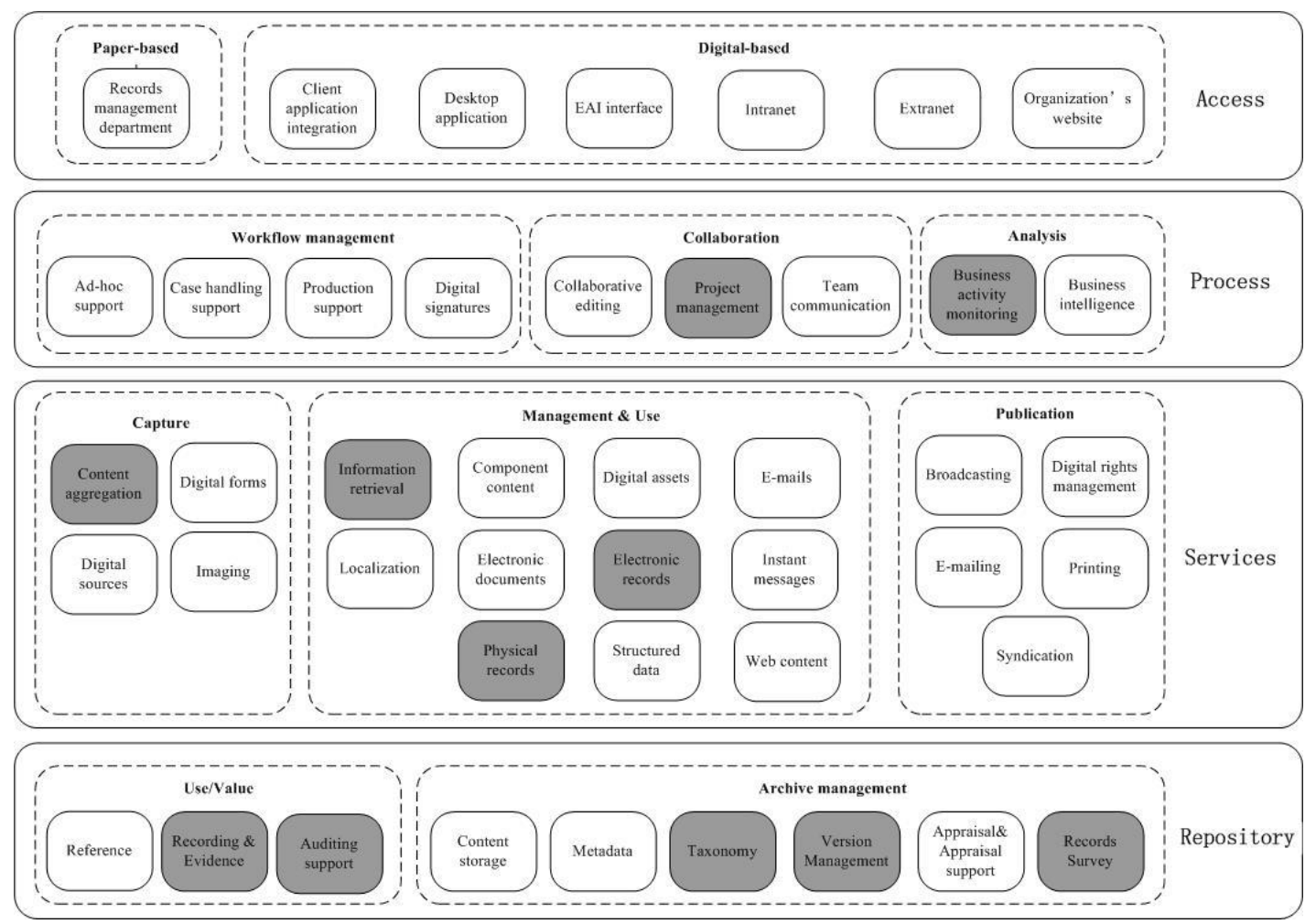

Figure 8: The needed ECM functionality in power plant extension construction archives project

In general, we found that the ECM functional model is a helpful tool in describing and segregating ECM functionality. After the addition functions, the model can be applied to both digital-based and paper-based content management. With the analysis support of the ECM functional model, the decision-making model that divides into both functionality related to core competencies and functionality not so related, provides general guidelines for the decision-making process and ensures that issues that may arise are considered in a logical manner. 


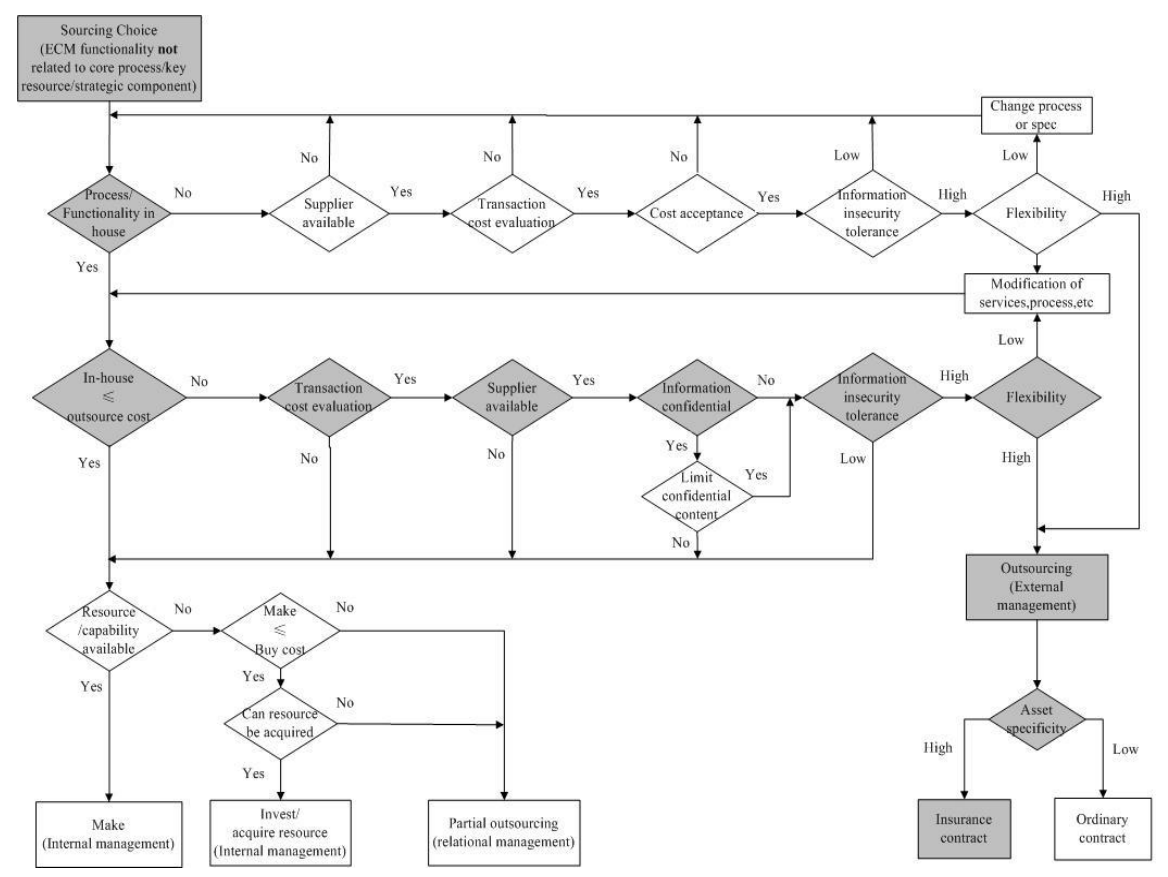

Figure 9: The ECM sourcing decision for the power plant extension construction archives project

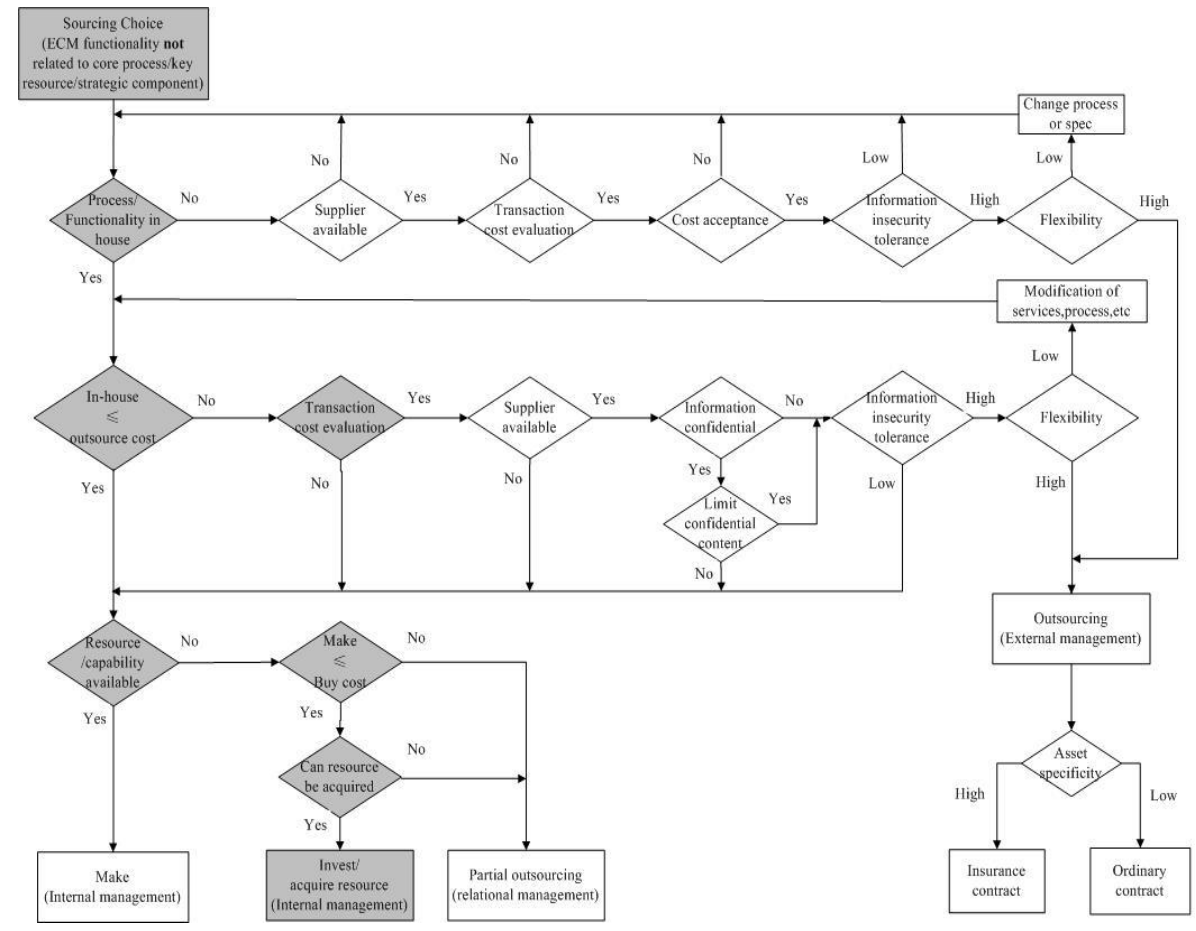

Figure 10: The content storage sourcing decision for the power plant extension 


\section{DISCUSSION AND CONCLUSION}

\section{Discussion}

During the case studies, we found the ECM functional framework can cover most of the ECM functions within organization. It is a useful to both segment and combination with ECM. The framework has been shown to be comprehensiveness in determining ECM outsourcing analysis and evaluation units.

All the links in the decision-making model are linear. During the case studies, we recognized that circumstance may arise where the decision maker begins at the starting point but stays in specific consideration, and may finally reach no sourcing result. Therefore, we add the Change process or spec component in the decision-making model by creating loops in figures both related to core competencies and not related to core competencies. The component of Modification of services, process, etc is also put into the model not related to core competencies. These loops enable decision makers to modify or separate the analysis unit being evaluated and start the process again.

After the case studies, the decision-making model for BPO of ECM has also shown appropriate guidance in the decision-making process. The core competency issue and the related considerations for information confidentiality, security, and management control and flexibility have shown high appropriateness in the decision-making process. Other considerations like process/functionality inhouse or not, costs comparison, and supplier availability are also helpful steps in the process. Also, the sequential order has been exemplified in our two case studies in light of the decision makers.

However, the lack of supplier solution evaluation, difficulty in cost estimation before the outsourcing transactions, and the self interest of the outsourcers cause limitations to the model. We observed from the feedback in these two cases that the model showed appropriateness to the ECM BPO decision process, but did not produce a successful or satisfying ECM BPO decision. While the availability of eligible suppliers would not be a problem in the evolving intermediate market of ECM, how to assess solutions the suppliers provided is a critical step in a successful ECM BPO. The solutions provided from the suppliers need to be evaluated against ECM objects of the enterprise, in order to make an outsourcer decision. Because a lack of supplier-solution evaluation in our model is a major defect, it needs future study. The enterprise may defer the BPO of ECM decision until suitable and acceptable solutions come under their consideration. Therefore, supplier-solution evaluation determines outsourcer choice, and when and how to conduct BPO of ECM.

Costs comparison exists in the model twice, but it is difficult to estimate or calculate cost in advance. The real estate corporation had not targeted all their ECM requirements before the contract drafting. A supplementary contract was made with the outsourcer for more specific needs after the test run of the ECM functions in the sales system. As a result, a set of unanticipated costs existed in this ECM BPO transaction. Therefore, requirement targeting should be undertaken before the cost comparison, to make the cost estimation more accurate.

Moreover, the self interest of the outsourcer has been a continued problem in outsourcing transactions. Although the enterprise intended to obtain new knowledge or new applications in ECM from the introduction of external resources, it is not clear about whether or how the new solution or technology fits the enterprise model. The outsourcer may insist on their original solutions and not investigate attentively on each specific enterprise model. This response will affect the compatibility of the ECM BPO outcomes. Therefore, further research on BPO is needed for those ECM processes/functionalities not existing in-house. 


\section{Conclusion}

The purpose of this study is to ascertain how to make a sourcing decision in ECM based on the complex and dynamic environment that an enterprise faces. This study sought to address the concerns: whether it is correct to conduct a specific ECM BPO; whether or not an ECM transaction should be outsourced; what allowances should be made for different ECM outsourcing decision strategies and different sourcing types. As a result, we focused on the development of a decisionmaking model for BPO in ECM. The first part on the ECM functional framework showed what functionality components or functionality combinations can be outsourced, and presented an important analysis tool for ECM. The second part on the decision-making model provided guidance for decision-making processes, and determined the factors to be considered in ECM BPO.

This paper's theoretical contributions are two-fold: first, the ECM function model is extended by including paper-based content based on the theory from records management and archives management. It extends the ECM research and leads to the integration of knowledge from related subjects from both electronic and non-electronic perspective; and second, our decision-making model for BPO of ECM adds new knowledge into the ECM field. The decision-making model fills the gap of outsourcing decision strategies in content management. For industry, the decision-making model provides guidance for practitioners on how to make decisions for BPO of ECM, and suggests factors and procedures. The sequential logic in our model is tested to be appropriate in ECM BPO decision making. It is an important guiding tool for those who make or are responsible for sourcing decisions in ECM, such as the CIOs.

One of the main limitations in this paper is the generalization of the decision-making model, concerning representativeness and transferability of cases (Goeken \& Börner, 2012). The two cases studied are both from Southern China and relate to the construction industry. It means the ECM BPO decision still needs to be modified or studied in countries other than China, and in industries other than construction, such as production and pharmacy. Furthermore, each of the two cases faced different circumstances, but two different decision-making paths did not cover all steps in the model. As well, the combined functional scope of each case did not cover all functionalities in the ECM model. All in all, future research is required to focus on extending the generalizability of the decisionmaking model. Another main limitation was the lack of supplier solution evaluation steps and the lack of solution assessment guidelines or criteria. Supplier solution evaluation and assessment can determine whether a BPO of ECM is successful and satisfying or not, in regards to cost estimation, outsourcer choice, and when and how to conduct an ECM BPO transaction. This domain will direct future IS ECM research, focusing on targeting the enterprise's ECM requirements, how to meet the ECM requirements and fulfill the objects of ECM, and what are the fundamental principles or basic elements in ECM solutions.

\section{REFERENCES}

Alvarez-Suescun, E. (2010) "Combining transaction cost and resource-based insights to explain IT implementation outsourcing”, Information Systems Frontiers, Vol 12, pp 631-645.

Aron, R. \& J.V. Singh (2005) “Getting off shoring right”, Harvard Business Review, Vol 83, pp 13543.

Aubert, B.A., Rivard, Suzanne. \& Party, Michel. (1996) "A transaction cost approach to outsourcing behavior: Some empirical evidence”, Information \& Management, Vol 30, pp 51-64.

Aubert, B. A. \& Weber, R. (2001) "Transaction cost theory, the resource-based view, and information technology sourcing decisions: A Re-examination of Lacity Etal.'s Find”. http://www2.hec.ca/gresi/documents/cahier0108.pdf accessed 2 July 2012. 
Aubert, B. A., Rivard, S. \& Patry M. (2004) “A transaction cost model of IT outsourcing”, Information \& Management, Vol 41, pp 921-932.

Barney, J. (1991) "Firm resources and sustained competitive advantage", Journal of Management, Vol 17, pp 99-120.

Barney, J., Wright, M., Ketchen, D. J. \& Jr. (2001) "The Resource-Based View of the firm: Ten years after 1991”, Journal of Management, Vol 27, pp 625-641.

Benbasat, I., Goldstein, D.K, \& Mead, M. (1987) "The case research strategy in studies of Information Systems", MIS Quarterly, Vol 11 No 3, pp 369-386.

Bonoma, T.V. \& Wong, K.B. (1985) “A Case Study in Case Research: Marketing Implementation”. Distributed by HBS Case Service, Harvard Business School.

Fine, C.H. \& Whitney, D.E. (1996) “Is the make-buy decision a core competence?". http://dspace.mit.edu/bitstream/handle/1721.1/1626/Make_Buy.pdf?sequence=2 accessed on 6 February 2013.

Gilley, K.M. \& Rasheed, A. (2000) "Making more by doing less: an analysis of outsourcing and its effects on firm performance", Journal of Management, Vol 26 No 4, pp 763-790.

Grahlmann, K.R., Helms, R.W., Hilhorst, C., Brinkkemper, S. \& Amerongen, S.V. (2012) "Reviewing Enterprise Content Management: a functional framework", European Journal of Information Systems, Vol 21, pp 268-286.

Grant, R.M. (1996) “Toward a knowledge-based theory of the firm”, Strategic Management Journal, Vol 17 (Winter Special Issue), pp 109-122.

Goeken M. \& Börner R. (2012) "Generalization in qualitative IS research approaches and their application to a case study on SOA", Australiasian Journal of Information Systems, Vol 17, No.2, pp79-108.

Harrison, J.S., Hitt, M.A., Hoskisson, R.E. \& Ireland, R.D. (2001) "Resource complementarity in business combinations: Extending the logic to organizational alliances", Journal of Management, Vol 27 No 6, pp 679-690.

Holcomb, T.R., Holmes, R.M. \& Hitt, M.A. (2006) "Diversification to achieve scale and scope: The strategic implications of resource management for value creation". In Advances in Strategic Management: Ecology and Strategy, JAI-Elsevier Science, UK.

Holcomb, T.R. and Hitt, M.A. (2007) "Toward a model of strategic outsourcing”, Journal of Operations Management, Vol 25, pp 464-481.

Kung, Chaang-Yung, \& Cheng, Chao-Ran. (2004) "Grey Assessing the Performance of Enterprise Outsourcing Management”, The Journal of Grey System, Vol 1, pp 63-72.

Lacity, M.C. \& Willcocks, L.P. (1995) "Interpreting Information Technology Sourcing Decisions From a Transaction Cost Perspective: Findings and Critique", Accounting, Management \& Information Technology, Vol 5 No 3-4, pp 203-244.

McIvor, R., Humphreys, P. and McKittrick, A. (2010) "Integrating the critical success factor method into the business process outsourcing decision", Technology Analysis \& Strategic Management, Vol 22 No 3, pp 339-360.

Morrow Jr, J.L., Sirmon, D.G., Hitt, M.A. \& Holcomb, T.R. (2005) "Creating value in the face of declining performance: firm strategies and organizational recovery", Strategic Management Journal, Vol 28 No 3, pp 271-283.

Mowery, D.C., Oxley, J.E. \& Silverman, B.S. (1996) "Strategic alliances and interfirm knowledge transfer". Strategic Management Journal, Vol 17, pp 77-91. 
Nordheim, S. \& Päivärinta, T. (2006) "Implementing enterprise content management: from evolution through strategy to contradictions out-of-the-box", European Journal of Information Systems, Vol 15, pp 648-662.

O’Callaghan, R. \& Smits, M. (2005) “A strategy development process for enterprise content management". In Proceedings of the 13th European Conference on Information Systems, May, pp 26-28.

Päivärinta, T. and Munkvold, B.E. (2005) "Enterprise content management: An integrated perspective on information managemet". In the proceddings fo the 38th Hawaii International Conference on System Sciences.

Parkhe, A. (1993) "Strategic alliance structuring: A game theoretic and transaction cost examination of interfirm cooperation". Academy of Management Journal, Vol 36 No 4, pp 794-829.

Pinkett, H.T. (1981) “American Archival Theory: The State of the Art”, The American Archivist, Vol 44 No 3, pp 217-222.

Quinn, J.B. \& Hilmer, F.G. (1994) “Strategic outsourcing”, Sloan Management Review, Vol 35 No 4, pp 43-55.

Real Story Group (2013) “Content Technology Vendor Map". http://www.realstorygroup.com/Research/Vendors accessed on 19 Feburary 2013.

Roethlisberger, F.J. \& Lombard, G.F.F. (1977) "The Elusive Phenomena: An autobiographical account of my work in the field of organizational behavior at the Harvard Business School." Harvard Business School.

Schellenberg, T.R. (1965) "The Appraisal of Modern Public Recordr", Bulletin the National Archives, Vol 8, pp 8.

Shy, O. \& Stenbacka, R. (2003) "Strategic outsourcing", Journal of Economic Behavior \& Organization, Vol 50, pp 203-224.

Smith, H.A. \& Mckeen, J.D. (2003) "Developments in practice VIII: Enterprise content management." Communications of Association for Information Systems, Vol 11, pp 1-26.

Spender, J. C. (1996) "Making Knowledge the Basis of A Dynamic Theory of the Firm", Strategic Management Journal, Vol 17, pp 45-62.

Stapleton, Richard. (1983) "Jenkinson and Schellenberg: A Comparison", Archivaria, Vol 17, pp 7585.

Tayles, M. \& Drury, Colin. (2001) "Moving from Make/Buy to Strategic Sourcing: The Outsource Decision Process", Long Range Planning, Vol 34, pp 605-622.

Tyrväinen, P., Päivärinta, T., Salminen, A. \& Iivari, J. (2006) "Characterizing the evolving research on enterprise content management", European Journal of Information Systems, Vol 15, pp 627-634.

Usman, M., Muzaffar, A.W \& Rauf, A. (2009) "Enterprise Content Management (ECM): Needs, Challenges and Recommendations", Computer Science and Information Technology, ICCSIT, 2nd IEEE International Conference, pp 283-289.

Wang. Li, Gwebu, K.L, Wang, J, \& Zhu, David.X. (2008) "The Aftermath of Information Technology Outsourcing: An Empirical Study of Firm Performance Following Outsourcing Decisions", Journal of Information Systems, Vol 22 No 1, pp 125-159.

Williamson, O.E. (1985) “The Economic Institutions of Capitalism”. Free Press, New York.

Yang, Dong-Hoon,, Kim, S., Nam, C. \& Min, Ja-Won (2007) "Developing a decision model for business process outsourcing”, Computers \& Operations Research, Vol 34, pp 3769 - 3778.

Zhao Yu Zhang (2008). English Reading on Archives Studies, Qunyan Press, Beijing. 